\title{
Development of Multilayer Perceptron Networks for Isothermal Time Temperature Transformation Prediction of U-Mo-X Alloys
}

Jesse M. Johns* and Douglas Burkes

jesse.johns@pnnl.gov, Phone: 509-375-6432

douglas.burkes@pnnl.gov, Phone: 509-372-4152

${ }^{*}$ Corresponding Author

Pacific Northwest National Laboratory, 902 Battelle Boulevard, P.O. Box 999, Richland, WA

99352

\begin{abstract}
In this work, a multilayered perceptron (MLP) network is used to develop predictive isothermal timetemperature-transformation (TTT) models covering a range of U-Mo binary and ternary alloys. The selected ternary alloys for model development are U-Mo-Ru, U-Mo-Nb, U-Mo-Zr, U-Mo-Cr, and UMo-Re. These model's ability to predict 'novel' U-Mo alloys is shown quite well despite the discrepancies between literature sources for similar alloys which likely arise from different thermalmechanical processing conditions. These models are developed with the primary purpose of informing experimental decisions. Additional experimental insight is necessary in order to reduce the number of experiments required to isolate ideal alloys. These models allow test planners to evaluate areas of experimental interest; once initial tests are conducted, the model can be updated and further improve follow-on testing decisions. The model also improves analysis capabilities by reducing the number of data points necessary from any particular test. For example, if one or two isotherms are measured during a test, the model can construct the rest of the TTT curve over a wide range of temperature and time. This modeling capability reduces the cost of experiments while also improving the value of the results from the tests. The reduced costs could result in improved material characterization and therefore improved fundamental understanding of TTT dynamics. As additional understanding of phenomena driving TTTs is acquired, this type of MLP model can be used to populate unknowns (such as material impurity and other thermal mechanical properties) from past literature sources.
\end{abstract}

Keywords

Artifical neural network; ANN, time-temperature-transformation; TTT; U-Mo alloys

\section{Introduction}

Metallic uranium $(U)$ alloys, specifically those capable of retaining the metastable gamma $(\gamma)-$ phase, are of considerable interest for use as a nuclear fuel material. This interest spans across various nuclear reactor designs and applications (e.g., light water reactor, research and test reactor, pulse reactor, fast breeder reactor) that represent a wide range of operational conditions (e.g., processing, thermal, flux, burnup). Alloys possessing the metastable $\gamma-U$ phase during both fabrication and irradiation have demonstrated adequate performance as a nuclear fuel material (e.g., swelling, coefficient of thermal expansion, corrosion, mechanical properties). During fuel fabrication and reactor operation, there is a propensity for metastable $\gamma$ phase to transition to thermodynamically stable, but mechanically disadvantageous, $\alpha$ and $\gamma^{\prime}\left(\mathrm{U}_{2} \mathrm{Mo}\right)$ phases [1], [2]. There is evidence, however, the phase reversal is possible under irradiation for a specific set of operational conditions.[3], [4]

(C) 2016. This manuscript version is made available under the Elsevier user license

http://www.elsevier.com/open-access/userlicense/1.0/ 
Transition metals in Groups V through VIII stabilize the $\gamma-\mathrm{U}$ phase below their respective equilibrium eutectioid isotherm, particularly $4 d$ and $5 d$ elements [5]. These elements are capable of forming solid solutions with the $\gamma \cup \mathrm{U}$ and the ability of the solute element to stabilize the gammaphase typically increases with atomic number as the $d$-electrons begin participating in bonding through hybridization with $s$ and $p$ atomic orbitals [6]. However, solubility decreases as the size difference of constituent atoms compared to $U$ atoms becomes larger. Increased bond strength promotes intermetallic compound formation that could have deleterious fabrication or performance impacts. Elements such as $\mathrm{Cr}, \mathrm{Nb}$, and $\mathrm{V}$ have acceptable solubility with respect to $\mathrm{U}$ without formation of intermetallics (up to $500^{\circ} \mathrm{C}$ ), while elements such as Al, Ti, Mo, and $\mathrm{Zr}$ have acceptable solubility with respect to $U$ but with formation of intermetallics. Elements such as $\mathrm{Cu}$, $\mathrm{Fe}$, and $\mathrm{Ni}$ have no solubility with $\mathrm{U}$ and form a range of intermetallics [7].

Uranium alloyed with greater than $7 \mathrm{wt} \% \mathrm{Mo}$, and most commonly $10 \mathrm{wt} \% \mathrm{Mo}$, have received the greatest attention as a metastable $\gamma-\mathrm{U}$ fuel alloy. Molybdenum has a wide range of solubility with $\mathrm{U}$ and the alloy offers acceptable swelling resistance, mechanical properties, and improved oxidation resistance over unalloyed U. However, U-Mo alloys are prone to inhomogeneity due to casting, stress corrosion cracking in various environments, and neutronic penalties associated with the neutron cross section of Mo. The ability to process U-Mo base alloys and the resultant properties may be enhanced by alloying with minor additions of a ternary transition metal. For example, minor additions of $\mathrm{Nb}$ to $\mathrm{U}-\mathrm{Mo}$ base alloys have historically shown decreased decomposition rates $(\gamma \rightarrow$ $\left.\alpha+\gamma^{\prime}\right)$, increased hot hardness, and progressively lower corrosion rates. Similarly, minor additions of Ru have shown a strong gamma-stabilizing effect that increased the corrosion behavior in high temperature water, although $\mathrm{Ru}$ forms $\mathrm{U}_{2} \mathrm{Ru}$ intermetallics that are extremely brittle. Other alloying additions, such as $\mathrm{Re}, \mathrm{Cr}$, and $\mathrm{Zr}$, may result in improved material behaviors, including phase stability, thermal expansion, resistance to humidity, tensile strength, neutronics, and fabricability [8].

The current work focuses on the impact of ternary additions to a U-Mo base alloy on time to transformation. Understanding the mechanisms of phase nucleation of alloys is challenging and often complicated by the lack of systematic, rigorous experimental data. Furthermore, nuclear material processing is costly and requires appropriate planning for execution so that the benefits of performing an experiment can be maximized. The development of a predictive model can allow researchers to narrow the scope of experimental testing in order to further refine data gaps and model uncertainties while reducing the cost and burden on performing such experiments.

Multilayer perceptron (MLP) networks, a class of artificial neural networks (ANN) commonly known today as deep neural networks, are capable of highly expressive representations of complex data and are now very commonly applied in many aspects of machine learning where data is routinely available. The ANN methodology has been applied to many fields in engineering, from developing models of thermophysical properties [9]-[11], nuclear material properties [12]-[14], and even evaluating nuclear criticality excursions [15]. In this work, an MLP network is evaluated as a potential predictive model of time-temperature-transformation (TTT) diagrams for various U-Mo alloys with ternary additions. The predictive model is used to assess the onset of gamma phase decomposition to determine the stabilizing/destabilizing characteristics of various ternary additions to a U-Mo base alloy. The purpose of developing an MLP network is to provide a predictive capability to explore the characteristics of these alloys to meet specific mission requirements for a given fuel alloy. The model can be used in conjunction with physical models in order to bound or support additional empirical model development, which will be the topic of follow-on work. However, these models are developed with the primary purpose of informing experimental decisions. These models allow test planners to identify areas of experimental interest; once initial tests are conducted, the model can be updated and further improve follow-on testing decisions [16]. This modeling capability further reduces the cost of experiments while also improving the richness of the results from the tests. The reduced costs could result in improved material characterization 
and therefore improved fundamental understanding of TTT dynamics. The development and application of the MLP network to U alloy TTT diagrams is explained in this paper.

\section{Material and Methods}

\subsection{Artificial Neural Networks}

Artificial neural networks are a class of numerical models inspired by the simplicity of biological neurons [17]. The ANN is not commonly programmed with prior physical rules or a priori knowledge on how a system behaves. Rather, it is a construct that learns to represent the behavior of a system on its own. It does this through a process of weight optimization provided a suitable fitness function is applied to the presented data. The advantage of ANNs compared to other machine learning approaches is that ANNs can be very robust to noise and missing data, and they can easily handle non-linear relationships between data. While the training process of an ANN can be quite computationally expensive, the computational effort of applying the resulting model is very small.

The framework of an ANN is actually quite simple conceptually and mathematically, see Figure 1. An MLP network is a class of ANN with more than one hidden layer. Each node of the neural network is often called a "neuron"; in order to prevent confusion with actual biological systems, "node" will be used in this paper.

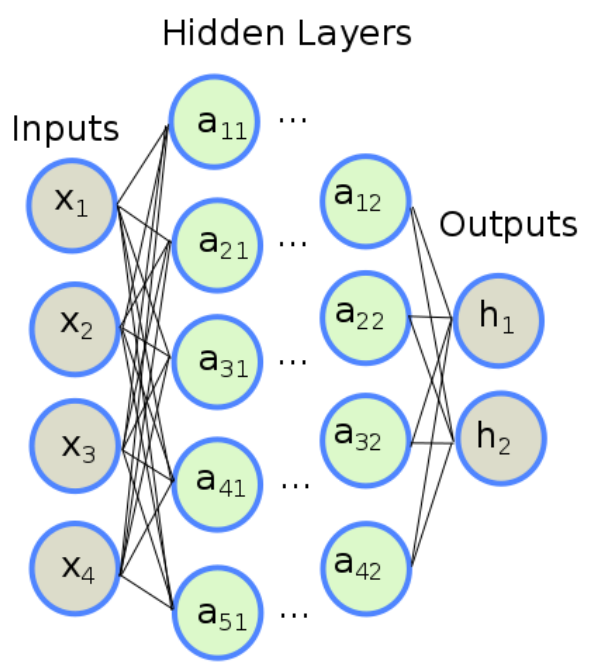

Figure 1.

A Generic Representation of an Artificial Neural Network

At each node (a schematic is shown in Figure 2) the total activation is computed by a summation of the weights and output from previous layer:

$$
y_{j}=\sum_{i=1}^{k} w_{i j} x_{i}
$$

where $y_{j}$ is the output of the node resulting from the summation of $w_{i j}$ weights and $x_{i}$ inputs. The subscripts $i$ and $j$ represent the node and hidden layer indicies, respectively. The output of a node feeds to the activation function (often called a non-linearity function) that determines the output signal of the node - hence the influence to biological neural networks. These activation functions 
can take many forms, most commonly the hyperbolic tangent or sigmoid functions. In this paper, a rectified linear unit is used, which takes the form:

$$
f(y)= \begin{cases}y & \text { if } y>0 \\ 0.0 & \text { otherwise }\end{cases}
$$

The advantage of a rectified linear unit over other common activation functions is that the gradient calculation is simplified and has been shown to greatly improve training times and thereby model performance [18], [19].

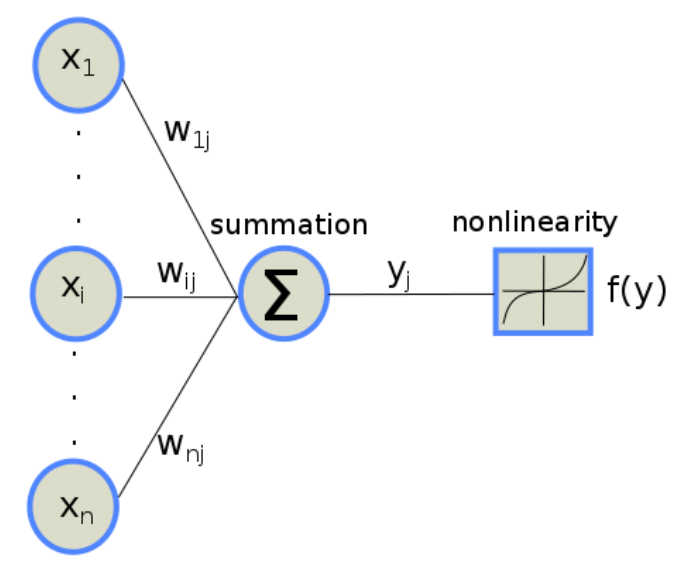

Figure 2.

Diagram of the Information Flow Within One Node

The number of hidden layers and number of nodes per hidden layer is determined during the training process to balance model accuracy during model training and testing. A detailed discussion is provided in Section 3.

\subsubsection{Training Procedure}

In this paper, three data sets are specified: training, testing, and validation. The training and testing data are used for training a model and the validation data is used to validate the model to neverbefore-seen data. The validation set is generated by completely removing a TTT curve from the training data set, so for example, when training the U-Mo binary model the U-10Mo curve, available in literature, would never seen by the model. This procedure ensures that the model that is trained on the remaining data is not overfitted, and therefore the model has some assurance that it can be used for predictive capabilities on novel data. Once the validation set is removed, the rest of the data is split randomly using a 70/30 fraction to make up the training/testing data, respectively.

The weights of the net are initialized with the Xavier method with the gain set to $\sqrt{2}$ and an L2 regularization of $1 \times 10^{-5}$ is applied to all layers [20]. Weight updates are performed with the Adam method using default parameters and each model is trained by minimizing a mean-squared error cost-function [21]. Training and verification error is monitored with a mean-squared error and the validation error is computed with:

$$
\frac{1}{N} \sum_{i=0}^{N}\left(\frac{x_{i}-\hat{x}_{i}}{x_{i}}\right)^{2}
$$


where $x_{i}$ is the actual validation data and $\hat{x}_{i}$ is the model's predicted result. Here, the index $i$ represented each data example presented to the model. During training, the training rate (relaxation factor on the weight update) is reduced with a schedule appropriate for the model complexity and if the validation error does not reduce after some number of iterations, the training is terminated. It is expected that as the training/testing error continues to converge the models will over-fit and the validation error on the validation set will begin to diverge. The weights from the minimum validation error are used to create the final model.

For each basic model, the inputs, normalized between -1 to 1 , are weight percent $U$, Mo, and the ternary alloying addition, and the isothermal temperature. More complex models, in the future, may also contain inputs of metallurgical processing variables such as homogenization temperature. The factors for normalization are saved with each model so they can be applied to novel data to ensure compatibility with the final model. The only output is the time for onset of $\alpha-U$ phase nucleation. The time of phase decomposition is on a log scale, so time is transformed to a linear scale for training purposes to reduce sensitivity to round-off errors.

\subsubsection{Special Data Preparation}

There are some special treatments for preparing the data sets for modeling that are briefly described here. First, the TTT data is interpolated using a $4^{\text {th }}$ order spline fit to generate a visibly identical curve to those provided in literature. The advantage of this approach is that, if more data is needed for training, the number of interpolation points can be increased. All curves in Section 2.2 are generated by the spline fit.

\subsection{Time-Temperature-Transformation Diagrams}

Time-temperature transformation (TTT) diagrams represent the phase transformation characteristics of an alloy under isothermal conditions. Decomposition of the $\gamma-U$ phase and transformation into undesirable $\alpha-\mathrm{U}$ phase is a concern during both fabrication and irradiation for most fuel applications. The current study is mainly focused on the impacts of processing temperatures and time on transformation characteristics of the alloy. A variety of methods can be used to measure the onset of phase transformation with a range of sensitivities, including but not limited to optical methods (microscopy and image analysis), phase analysis (x-ray and neutron diffraction), electrical analysis (resistance), mechanical analysis (hardness), and thermal analysis (dilatometry). Results can vary depending upon the experimental method employed as well as the threshold defined for onset of nucleation. For this study, a threshold of 5 weight percent of $\alpha-U$ phase in solution was considered to be the onset of nucleation, which is consistent with the expected sensitivities of the measurement techniques by works in which the TTT data was collected.

The TTT data is gathered from four independent sources and a compilation of the data is provided in Table A.1 of the Appendix. Notably, Table A.1 provides the results of the TTT nose (the time and the corresponding temperature of the onset of $\alpha$-phase nucleation) as a quantitative reference. In Peterson et al., 1964 (referred to as Peterson in the rest of this paper) initiation of $\gamma$ phase decomposition was measured by multiple methods [5]. For high temperature measurements, resistance measurements and metallography were predominately used. For low temperature measurements, resistance and hardness measurements were used. X-ray diffraction, was only used to verify the phase identification. The authors noted that metallography was inferior for low temperature measurements and that resistometric methods were the most sensitive over the 
entire range of measurements. Cabane and Donze (referred to as Cabane) used metallography and dilatometer measurements along with $\mathrm{x}$-ray diffraction for phase identification [22]. Repas et al. (referred to as Repas) similarly used metallographic, hardness, dilatometric, and $\mathrm{x}$-ray techniques [23]. Lastly, Steiner et al. (referred to as Steiner) measured phase transformation by neutron diffraction - the most accurate method of the works used in this study capable of modeling the initiation of $\alpha$-phase nucleation to $0.1 \%$ [24]. The work of Steiner also produced a full temporal history of $\alpha$-phase growth. Some level of disagreement is expected as the methods vary between the authors but also the experimental conditions and $U$ alloy preparation varies between the works.

\subsection{TTT Diagram Data}

The baseline U-Mo binary phase TTT is shown in Figure 3 for each reference. As expected, as Mo content is increased, the $\alpha$-U phase nucleation time also increases. Immediately noticeable is that the nose of each TTT curve (the region that results in the most rapid $\gamma-U$ phase decomposition) sits between $500-520^{\circ} \mathrm{C}$, noting that this is approximately $40^{\circ} \mathrm{C}$ below the eutectoid temperature of $565^{\circ} \mathrm{C}$ [25]. Good agreement between Cabane and Steiner is observed for $8.13 \mathrm{wt} \%$ and $8 \mathrm{wt} \%$ Mo, respectively. Poor agreement between Cabane and Peterson is observed for most of the curves in the 5-8 wt\% range. The lack of agreement can be attributed to different conditions within the experimental setup and preparation of the U-Mo alloy. Impurity levels in the alloys were not reported. In addition, as reported by Steiner, varying initial conditions of the microstructure could significantly impact the dynamics of the isothermal transformation. More study is required on the influence of processing conditions on $\gamma-U$ phase decomposition before addressing the observed disparities further.

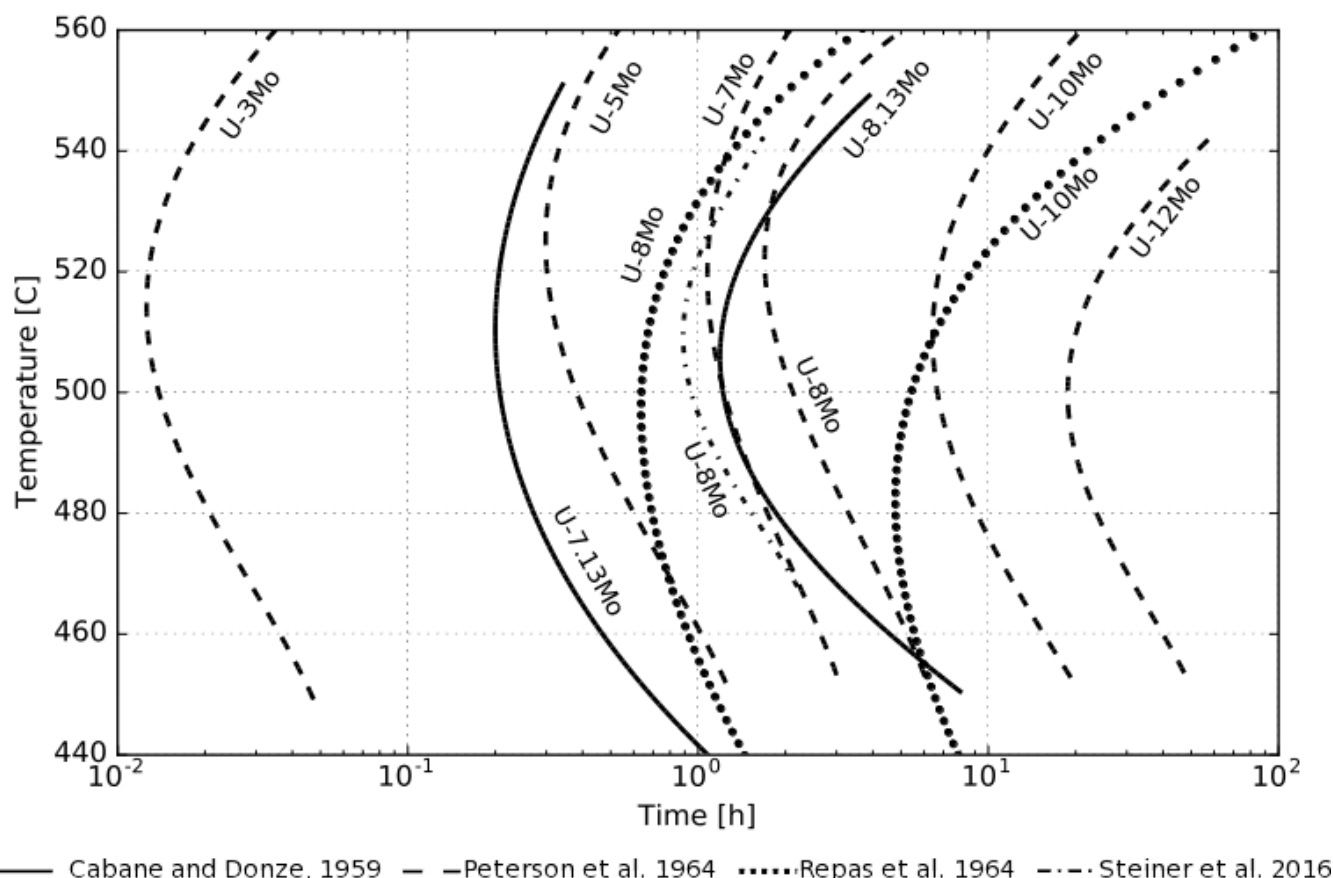

Figure 3.

Reproduced U-Mo binary alloy TTT based on the works of Cabane and Donze, Peterson et al., Repas et al., and Steiner et al

Additions of Ru to a U-Mo alloy have not previously been observed to exhibit improvements on corrosion resistance, or hot hardness, but were observed to slightly depress the transformation temperature [8]. TTT curves for the U-Mo-Ru ternary alloy are shown in Figure 4 and compared to the TTT curves for U-5/8/10 wt\% Mo. The addition of Ru in the base U-Mo alloy further stabilizes the gamma phase and increases the time for $\alpha-\mathrm{U}$ phase nucleation. The U-5.3Mo-1.9Ru and U- 
6.2Mo-0.49 Ru achieve comparable and slightly improved phase stability over U-8Mo at temperatures above $490^{\circ} \mathrm{C}$. It's interesting to note that the U-7.2Mo-0.95Ru alloy achieves performance similar to U-10Mo. This Ru ternary alloy decreases the nucleation time by $29 \%$. The nose of the Ru alloy is at $511^{\circ} \mathrm{C} / 4.63$ hours compared to $509^{\circ} \mathrm{C} / 6.55$ hours for $\mathrm{U}-10 \mathrm{Mo}$. Another interesting characteristic is the change in temperature dependence with the U-6.3Mo-1.9Ru alloy, which achieves better or similar stability than U-7.2Mo-0.95Ru at temperatures above $520^{\circ} \mathrm{C}$.

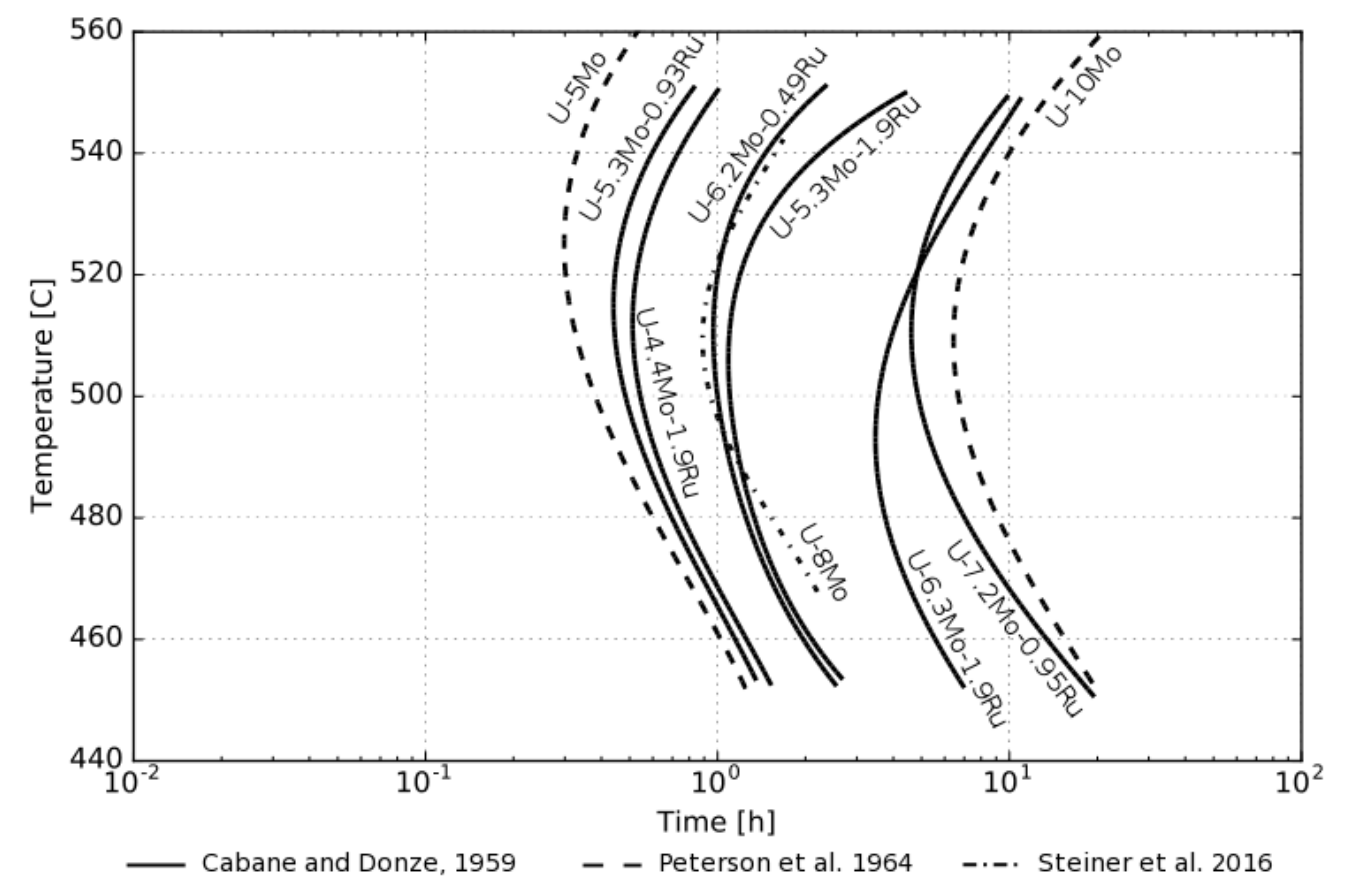

Figure 4.

Reproduced U-Mo-Ru ternary alloy TTT based on the works of Cabane and Donze and Peterson et al.

Addition of $\mathrm{Zr}$ to a U-Mo alloy has been observed to decrease phase stability, hot hardness, corrosion resistance (in water), and premature transformation [8]. However, Zr may be a useful addition in air environments where humidity is a concern, owing to the gettering ability of hydrogen. The TTT curves for the U-Mo-Zr ternary alloy are shown in Figure 5. The time to gamma-phase decomposition with $\mathrm{U}-7.23 \mathrm{Mo}-0.86 \mathrm{Zr}$ is slightly greater than $\mathrm{U}-7 \mathrm{Mo}-1 \mathrm{Zr}$; the shapes are very similar indicating acceptable agreement between the works of both authors. In general, the kinetics of the $\gamma \mathrm{U}$ phase transformation is accelerated by formation of $\mathrm{ZrMo}_{2}$ that ultimately depletes Mo within the $\mathrm{U}$ matrix [5]. The $\mathrm{Zr}$ addition results in a significant destabilization of the gamma-phase. The U$10 \mathrm{Mo}-1 \mathrm{Zr}$ curve is similar to $\mathrm{U}-7 \mathrm{Mo}$, and there is a factor of ten reduction of the transformation time between U-10Mo (6.56 hours) and U-10Mo-1Zr (0.656 hours). Likewise, the TTT of U-5Mo-1Zr and $\mathrm{U}-7 \mathrm{Mo}-2 \mathrm{Zr}$ are very similar. The addition of $\mathrm{Zr}$ decreases the temperature of the TTT nose and decreases the time to $\alpha$-phase nucleation. 

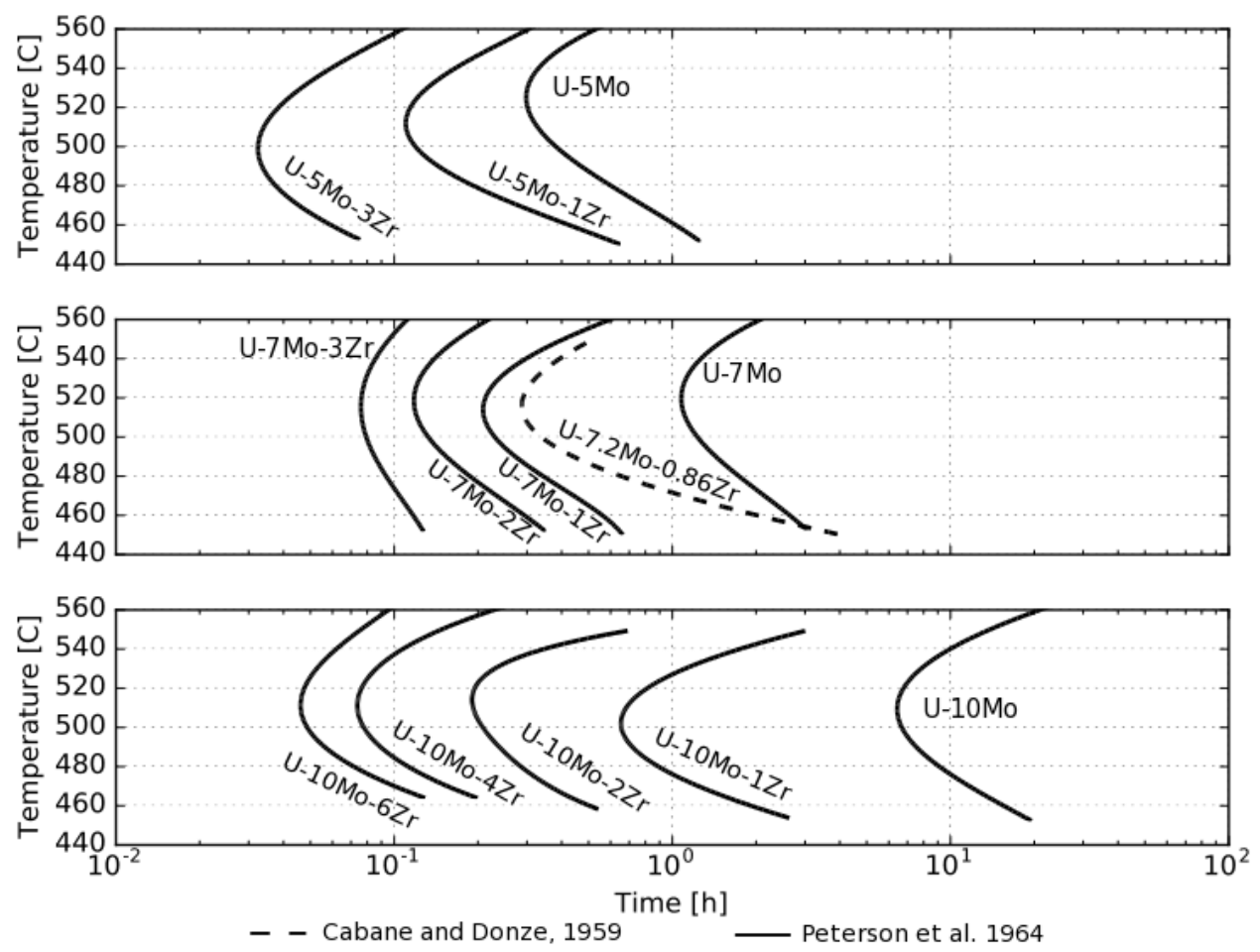

Figure 5.

Reproduced U-Mo-Zr ternary alloy TTT based on the works of Cabane and Donze and Peterson et al.

Additions of $\mathrm{Nb}$ to a U-Mo alloy have been observed to increase thermal $\gamma-\mathrm{U}$ phase stability and hot hardness, and generally decreased corrosion rates in water [6]. The TTT curves for the U-Mo-Nb ternary alloy are shown in Figure 6 . The phase decomposition of U-5Mo-5Nb is significantly more rapid than U-5Mo based on the work of Peterson. However, the increased stability resulting from an increase in $\mathrm{Nb}$ from the $\mathrm{U}-5.3 \mathrm{Mo}-0.85 \mathrm{Nb}$ to $\mathrm{U}-5.4 \mathrm{Mo}-1.7 \mathrm{Nb}$ suggests a different behavior entirely. In addition, the phase decomposition of U-7.26Mo-1.142Nb is similar to U-8Mo and $\mathrm{U}$ $5.35 \mathrm{Mo}-1.73 \mathrm{Nb}$ is similar to $\mathrm{U}-5 \mathrm{Mo}$, though the nose of $\mathrm{U}-5 \mathrm{Mo}$ shifts upward by $40^{\circ} \mathrm{C}$. Therefore, the behavior of $\mathrm{Nb}$ as a ternary alloying component for improving $\gamma-\mathrm{U}$ phase stability is somewhat inconclusive considering the behavioral differences between the works. 


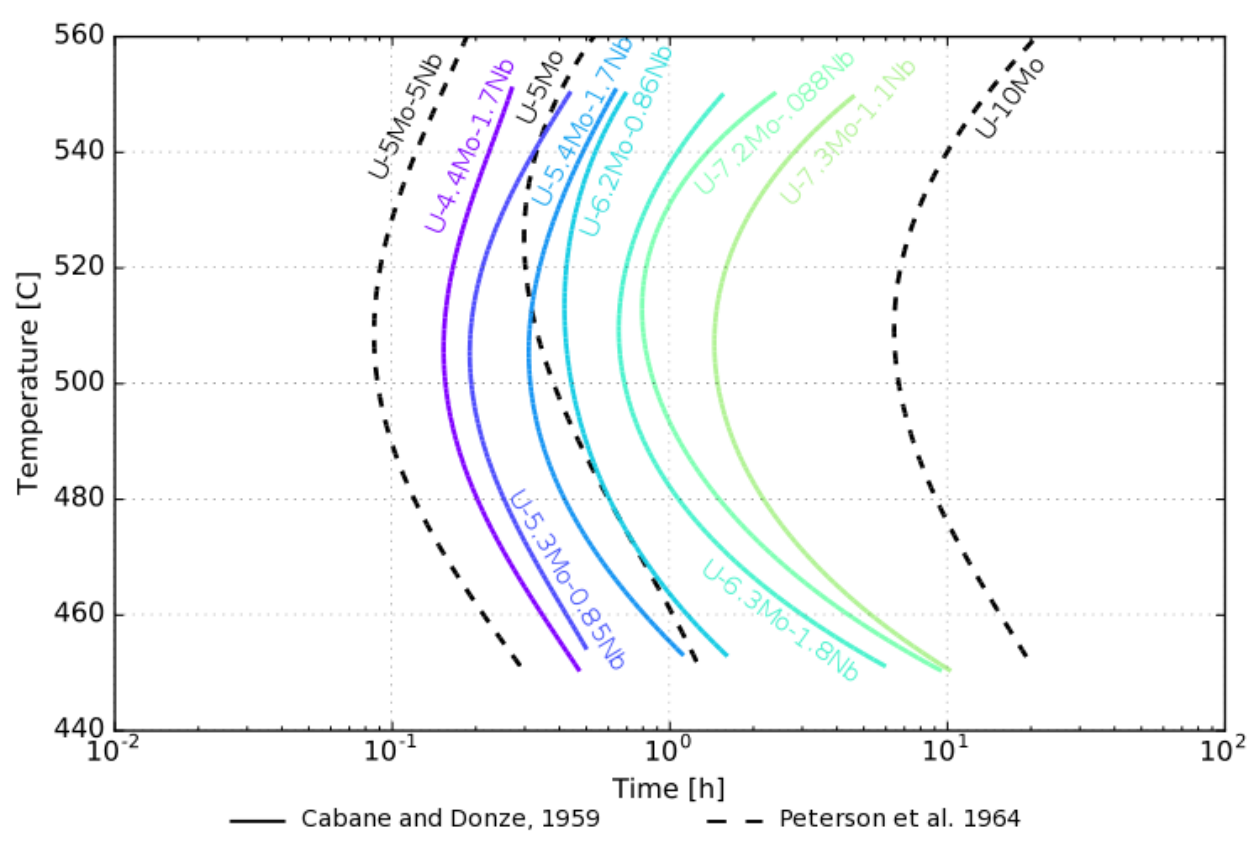

Figure 6. Reproduced U-Mo-Nb ternary alloy TTT based on the works of Cabane and Peterson.

Additions of $\mathrm{Cr}$ to a U-Mo alloy have been observed to have a negligible effect on general behavior, with slight increase in $\gamma \mathrm{U}$ phase stability [8]. The TTT diagram for the U-Mo-Cr ternary alloy is shown in Figure 7. There is little data on this ternary alloy; however, addition of $\mathrm{Cr}$ results in a slight stabilization of the $\gamma$-phase and reduction of the nose of the $\gamma \mathrm{U}$ phase transformation temperature. In particular, at temperatures less than $485^{\circ} \mathrm{C}$, both $\mathrm{U}-6.3 \mathrm{Mo}-0.49 \mathrm{Cr}$ and $\mathrm{U}-7.2 \mathrm{Mo}-0.29 \mathrm{Cr}$ have improved stabilization over U-7Mo while U-7.2Mo-0.29Cr also exhibits improvement over U-7Mo at a temperature above $520^{\circ} \mathrm{C}$. At temperatures less than $460^{\circ} \mathrm{C}, \mathrm{U}-7.3 \mathrm{Mo}-0.49 \mathrm{Cr}$ becomes equivalent to $\mathrm{U}-10 \mathrm{Mo}$. Chromium is by-far the lightest element assessed in this paper, so the atomic density of $\mathrm{Cr}$ within the alloy is greater than the other ternary alloying elements.

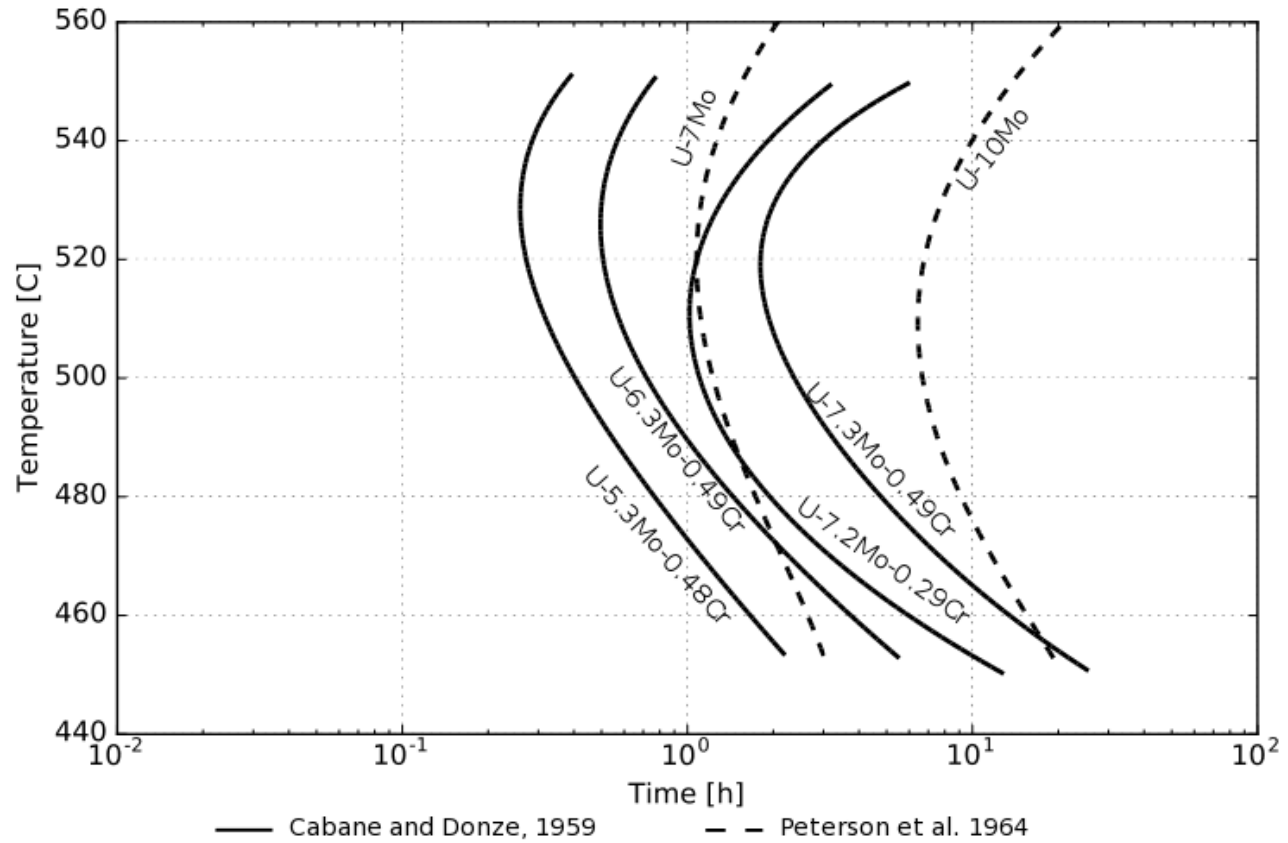

Figure 7. Reproduced U-Mo-Cr ternary alloy TTT based on the works of Cabane and Peterson. 
Lastly, the TTT diagram for the U-Mo-Re ternary alloy is shown in Figure 8. There are fewer available data for Re than for $\mathrm{Cr}$. The stabilization of $\mathrm{Re}$ is slightly more significant than $\mathrm{Cr}$, but less so than Ru and Mo. At temperatures above and below $525^{\circ} \mathrm{C}$ and $470^{\circ} \mathrm{C}$, respectfully, U-6.2Mo1.7Re achieves better stabilization than U-7Mo. At temperatures above $545^{\circ} \mathrm{C}$, both U-7.2Mo1.7Re and U-6.2Mo-3.4Re improve transformation times over $\mathrm{U}-10 \mathrm{Mo}-$ a significant reduction in Mo. On the contrary, Re also has a larger nuclear capture cross-section by at least a factor of 30 , a deleterious impact on nuclear performance of the fuel. Rhenium has a much larger atomic mass than any other evaluated ternary addition; therefore, the atomic density of Re is quite small comparatively. With these two considerations taken into account, the total weighted capture crosssection of Re alloys is on the order of a factor of two greater than other comparable alloys.

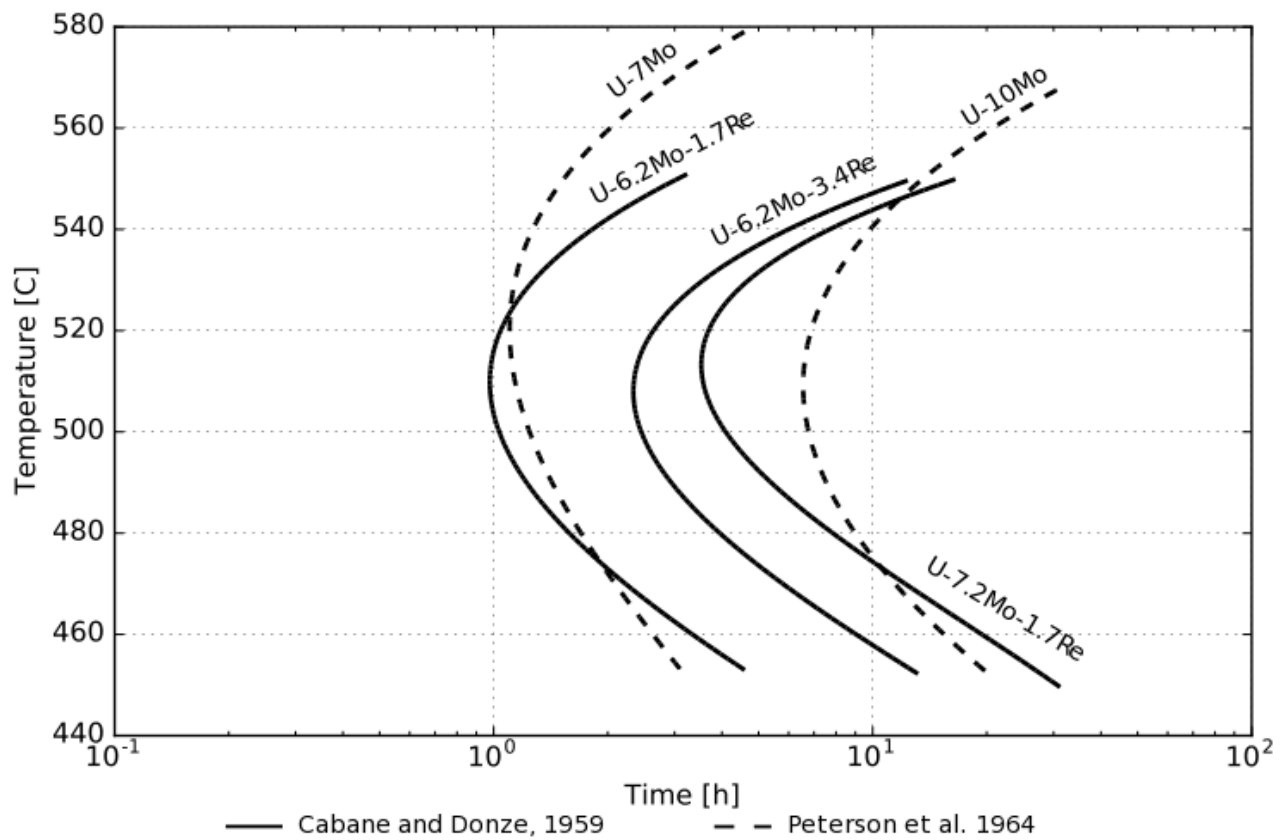

Figure 8. Reproduced U-Mo-Re ternary alloy TTT based on the works of Cabane and Peterson.

\section{Results and Discussion}

The predictions made by the trained models are discussed in this section. For evaluation purposes, all predictions are performed assuming a temperature of $500^{\circ} \mathrm{C}$, unless otherwise specified, and compared to experimental data at those temperatures.

\subsection{Selection of Hidden Layers and Nodes}

The selection of the number of layers and nodes per layer come as a balance of model training cost and validation accuracy. The more complex a model becomes the greater its tendency to overfit the data and therefore the worse its ability to adjust to novel conditions. This is similar to increasing the polynomial order on a polynomial fit of some set of data. A high order polynomial can match training data quite well but as the order increases, the fit quickly becomes incapable of predicting novel data outside, or even inside, the established boundary conditions. Therefore, plotting 
predictions of the trained model on the validation set is suggested to ensure the model is generalizing well enough to the training data in order to produce suitable predictions (see Figure 9). This figure also shows the training, testing, and validation error as a function of training iteration. At iteration 602, the validation error is a minimum, so the weight values at that iteration are used for this particular model. Since the initialization of weights and the split of training data are both random, a total of twenty models are trained with the same parameters and the one with the lowest validation error is selected.
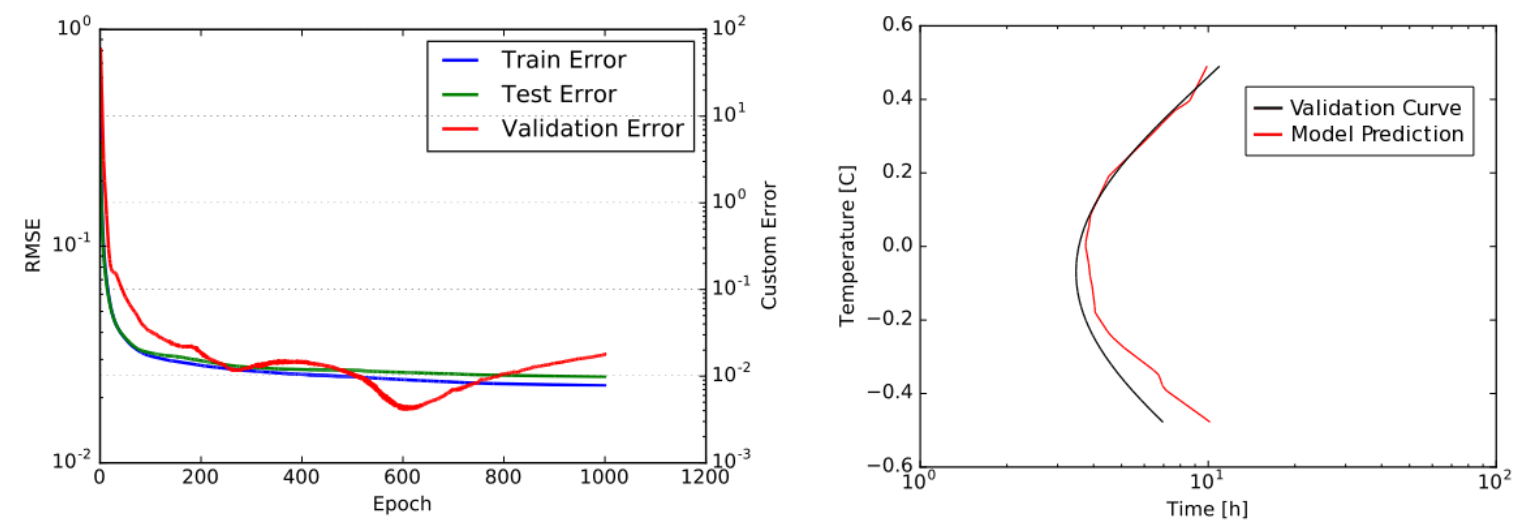

Figure 9. Training, testing, and validation error during training for U-Mo-Ru model (left) and the model prediction versus the validation data for U-6.3Mo-1.9Ru with normalized temperature units.

While the process of performing a grid search to optimize the number of layers and nodes per layer is ideal, the computational cost for such a procedure is prohibitive. The random nature of ANN training, resulting from random initialization of weights, requires many models to be developed for each set. In addition, the number of permutations quickly makes this method computationally burdensome. The parameter selection was performed using operator judgment rather than a quantitative metric; therefore, additional optimization on these parameters is likely possible. The final neural network for ternary alloy models has five hidden layers with 16, 40, 80, 80, and 80 nodes while the binary model has four hidden layers with $18,24,36$, and 60 nodes, respectively.

\subsection{U-Mo Binary}

The U-Mo model is trained with both $\mathrm{U}-10 \mathrm{Mo}$ datasets removed for validation. Considering the consistent agreement between the authors on other alloy measurements, the U-Mo7.13 curves appears to be anomalous. Despite this, all curves (save those removed for validation) are used for model training. The prediction of the final U-Mo model is shown in Figure 10, where the $5 \% \alpha$ phase nucleation time at a process temperature of $500^{\circ} \mathrm{C}$ is shown as a function of the Mo weight percent. Notably, the stabilization property of Mo begins to increase more dramatically after approximately $9 \mathrm{wt} \%$. Overall, the prediction agrees quite well with values reported in literature. The relative percent error compared to literature values is shown in Figure 11 and tabulated in Table 1 for temperatures 480,500 , and $520^{\circ} \mathrm{C}$. The validation sets removed during training (both $\mathrm{U}-10 \mathrm{Mo}$ curves) are indicated by bold print face. The most notable errors arise in the 7-8 wt\% range, which is expected due to the disagreement in the literature. Figure 11 should be viewed with caution as contour features do not map well when there are multiple values at each Mo w\% and temperature location as is the case with $\mathrm{U}-10 \mathrm{Mo}$, for example. However, this figure does 
provide a conceptual visualization of the expected prediction error as a function of temperature and Mo w\%.

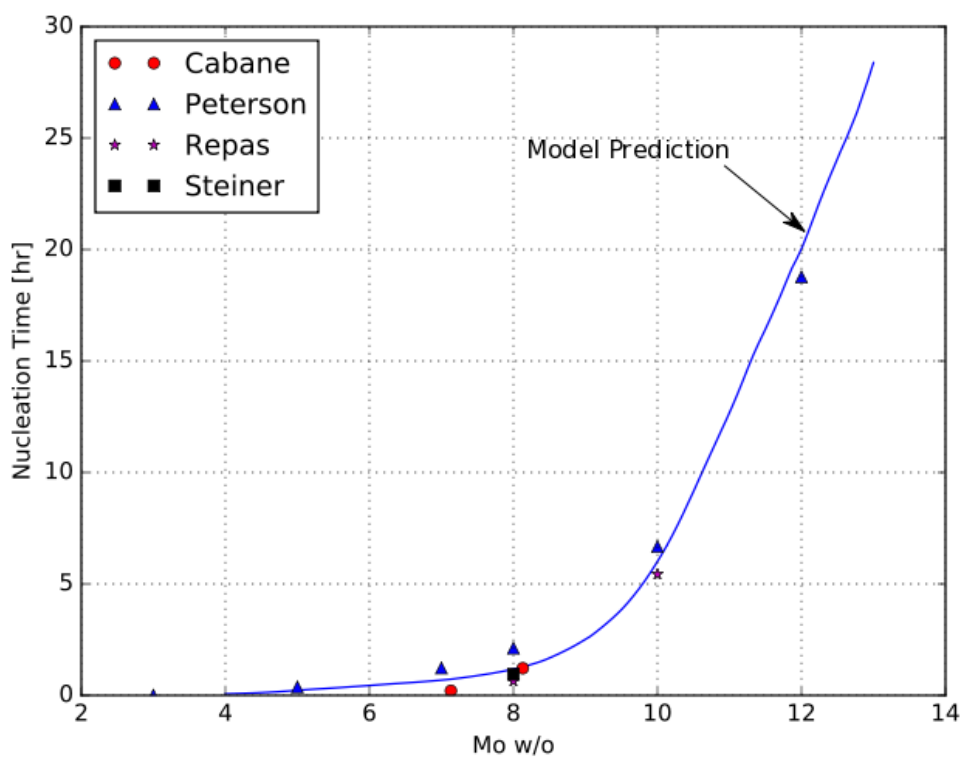

Figure 10. Prediction of nucleation time for U-Mo binary phase at a processing temperature of $500^{\circ} \mathrm{C}$.

Table 1. The percent relative error of the model prediction at three different temperatures compared to literature data. The significant figures reported in this table are not indicative of experimental accuracy but are used for numerical comparison only.

\begin{tabular}{|c|c|c|c|c|c|c|c|c|c|}
\hline \multirow[b]{2}{*}{ Mo w/o } & \multicolumn{3}{|c|}{$480 C$} & \multicolumn{3}{|c|}{$500 \mathrm{C}$} & \multicolumn{3}{|c|}{$520 \mathrm{C}$} \\
\hline & $\begin{array}{l}\text { Prediction } \\
\text { [hr] }\end{array}$ & $\begin{array}{l}\text { Experiment } \\
\text { [hr] }\end{array}$ & Error & $\begin{array}{l}\text { Prediction } \\
\text { [hr] }\end{array}$ & $\begin{array}{l}\text { Experiment } \\
\text { [hr] }\end{array}$ & Error & $\begin{array}{l}\text { Prediction } \\
\text { [hr] }\end{array}$ & $\begin{array}{l}\text { Experiment } \\
\text { [hr] }\end{array}$ & Error \\
\hline 3 & 0.032 & 0.021 & 55.5 & 0.022 & 0.014 & 62.3 & 0.019 & 0.013 & 44.8 \\
\hline 5 & 0.327 & 0.602 & -45.8 & 0.230 & 0.381 & -39.7 & 0.184 & 0.302 & -39.0 \\
\hline 7 & 0.998 & 1.735 & -42.5 & 0.685 & 1.230 & -44.3 & 0.610 & 1.077 & -43.3 \\
\hline 7.13 & 1.056 & 0.272 & 288.8 & 0.725 & 0.207 & 249.9 & 0.656 & 0.206 & 217.8 \\
\hline 8 & 1.743 & 1.533 & 13.7 & 1.180 & 0.947 & 24.6 & 1.182 & 0.964 & 22.7 \\
\hline 8 & 1.743 & 0.695 & 150.7 & 1.180 & 0.639 & 84.6 & 1.182 & 0.768 & 53.9 \\
\hline 8 & 1.743 & 3.297 & -47.1 & 1.180 & 2.123 & -44.4 & 1.182 & 1.700 & -30.5 \\
\hline 8.13 & 1.911 & 1.860 & 2.8 & 1.282 & 1.218 & 5.2 & 1.303 & 1.362 & -4.3 \\
\hline 10 & 7.528 & 9.124 & -17.5 & 6.008 & 6.679 & -10.0 & 6.532 & 6.772 & -3.5 \\
\hline 10 & 7.528 & 4.796 & 57.0 & 6.008 & 5.438 & 10.5 & 6.532 & 8.807 & -25.8 \\
\hline 12 & 25.560 & 23.615 & 8.2 & 20.025 & 18.778 & 6.6 & 28.917 & 24.565 & 17.7 \\
\hline
\end{tabular}




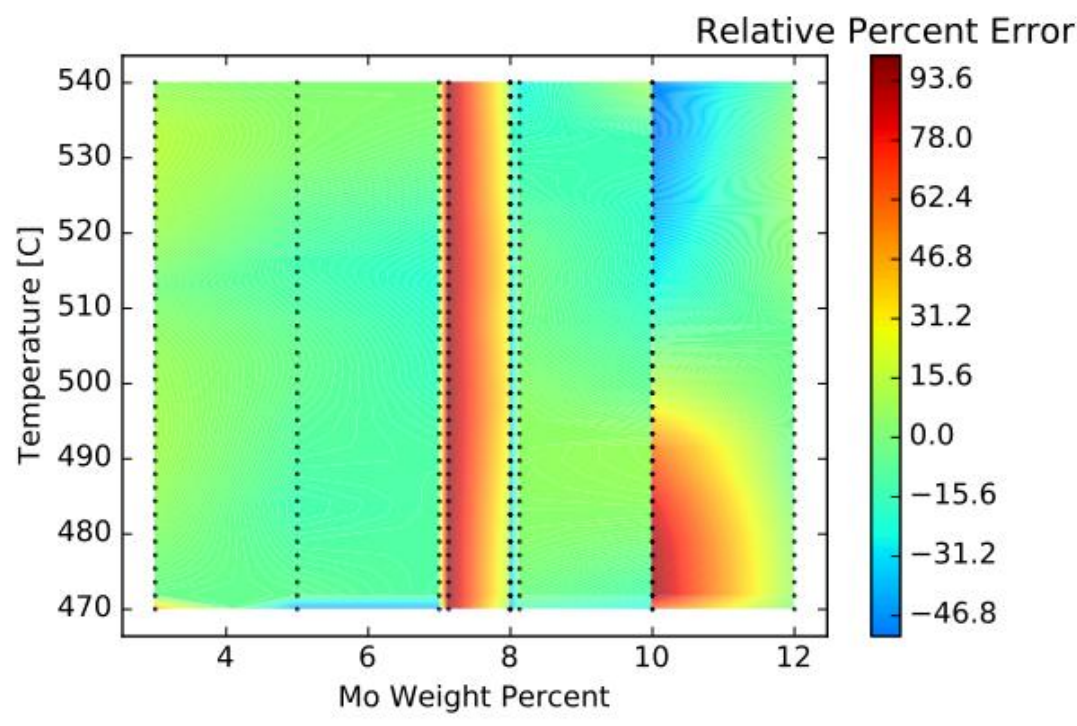

Figure 11. The maximum relative percent error between the predictive model and experimental data (shown with black points) as a function of Mo weight percent and temperature. The error is cut-off at $+/-100 \%$ and a second order fit is used to interpolate between data points to produce the contour.

\subsection{Ternary Alloys}

The results for the predictive ternary models are shown in Figure 12 for a temperature of $500^{\circ} \mathrm{C}$, where the time for $5 \mathrm{w} \% \alpha$-phase nucleation is shown by the colorbar as a function of Mo and ternary weight percent. The points correspond to experimental data; individual sources from literature are not annotated to reduce the clutter on these figures. A lower cut-off of 0.1 hours and a higher cut-off of 100 hours is used to limit the results to better illustrate the range of interest. In keeping the axes consistent, there is a varying degree of extrapolation outside the available literature. Some alloys, like U-Mo-Zr, have alloys well outside $4 \mathrm{w} \% \mathrm{Zr}$, but others, like U-Mo-Cr, do not exceed $1 \mathrm{w} \%$. A particular case where the models might not be appropriate for extrapolation is with the U-Mo-Ru model. It can be seen that the behavior of the model changes dramatically when Mo $>7 \mathrm{w} \%$ and $\mathrm{Ru}>2 \mathrm{w} \%$.

The behavior of the $\alpha$-phase transformation onset provides insight on the impact of $\gamma$-phase stablization resulting from the addition of a ternary species. A ternary addition that results in a positive slope (or a negatively slopped contour line) is considered to be stablizing in general, not necessarily that it is further stablizing the $U$-Mo alloy. Lines of constant $U$ weight percent are shown for context, and any change in slope from the constant $U$ line is interpreted as an increase/decrease in phase stabilization compared to U-Mo. Addition of $Z r$ is confirmed to be a powerful destabilizer, and Ru has the strongest stabilization effect. Addition of $\mathrm{Nb}$ appears to be inconclusive from the literature survey; however, the predictive model appears to demonstrate some stabilization properties when added to an alloy with greater than about $5.5 \mathrm{w} \%$ Mo. The models also represent $\mathrm{Cr}$ as a stabilizer. The models do predict that concentrations greater than 1 w\% of $\mathrm{Cr}$ with less than $5 \mathrm{w} \%$ of Mo are no longer stabilizing; however, these predictions are outside of the available literature data. The additions of $\mathrm{Re}$, and to some degree $\mathrm{Cr}$, appear to be subsitutionally neutral with Mo. Ru is the only ternary element that appears to further increase $\gamma$ phase stabilization in conjuction with Mo. 

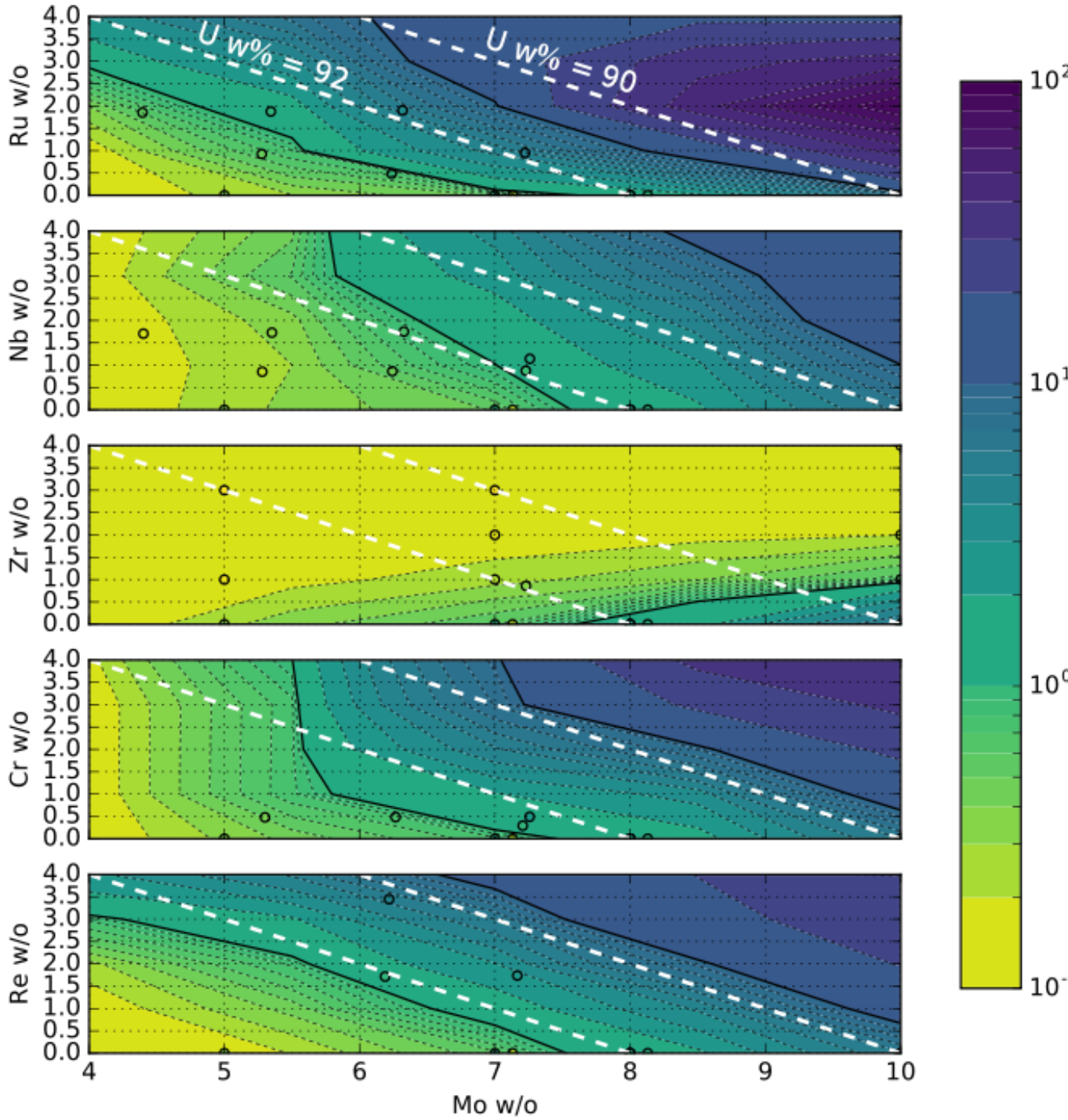

Figure 12.

Time to nucleation of $\alpha$-phase predictions from models for U-Mo-Ru, U-Mo-Nb, U-Mo-Zr, U-Mo-Cr, U-Mo-Re at $500{ }^{\circ} \mathrm{C}$ with experimental data shown by data points using the same color scale. Results are bounded between 0.1-100 hours. Lines of constant $U$ weight percent are shown for $90 \%$ and $92 \%$.

Table 2 shows the relative percent error when comparing predictive models at $500^{\circ} \mathrm{C}$ to literature values. The validation datasets used are highlighted. Note that the error on these sets are comparatively quite low compared to the error between the model and the training sets. This arises from the bias associated with selecting the model that best matched the validation set. In general, the errors between the models and experimental data lie below $20 \%$, with particularly high error with the U-Mo-Cr and U-Mo-Nb models. The greater error for Nb alloys is likely a result of conflicting behavior noted in the literature. Validation sets, for most ternary alloys, were selected such that the predictive model would have to extrapolate. For example, the U-Mo-Re model is trained with data from alloys with 1.72 and $1.74 \mathrm{w} \%$ of Re. Still, the model is capable of 
extrapolating out to the $3.45 \mathrm{w} \%$ Re validation curve. The performance of the models on these conditions provide additional confidence in application.

Table 2.

Results of model prediction compared to literature values at $500^{\circ} \mathrm{C}$ showing the Mo/ternary composition, the prediction and literature time to nucleation, and the percent relative error. The significant figures reported in this table are not indicative of experimental accuracy but are used for numerical comparison only.

\begin{tabular}{|c|c|c|c|c|}
\hline Mo & $\mathrm{Zr}$ & $\begin{array}{l}\text { Prediction } \\
\text { [hr] }\end{array}$ & $\begin{array}{l}\text { Experiment } \\
\text { [hr] }\end{array}$ & Error \\
\hline 5.00 & 1.00 & 0.13 & 0.12 & 8.17 \\
\hline 5.00 & 3.00 & 0.04 & 0.03 & 9.40 \\
\hline 7.00 & 2.00 & 0.13 & 0.13 & -2.93 \\
\hline 7.00 & 1.00 & 0.26 & 0.23 & 12.41 \\
\hline 7.00 & 3.00 & 0.07 & 0.08 & -5.85 \\
\hline 7.23 & 0.86 & 0.31 & 0.34 & -9.35 \\
\hline 10.00 & 4.00 & 0.07 & 0.08 & -6.68 \\
\hline 10.00 & 1.00 & 0.64 & 0.66 & -1.83 \\
\hline 10.00 & 6.00 & 0.04 & 0.05 & -7.87 \\
\hline 10.00 & 2.00 & 0.20 & 0.21 & -4.96 \\
\hline Mo & $\mathbf{R u}$ & $\begin{array}{l}\text { Prediction } \\
\text { [hr] }\end{array}$ & $\begin{array}{l}\text { Experiment } \\
\text { [hr] }\end{array}$ & Error \\
\hline 4.39 & 1.85 & 0.47 & 0.54 & -13.11 \\
\hline 5.28 & 0.93 & 0.56 & 0.48 & 16.06 \\
\hline 5.34 & 1.88 & 1.15 & 1.10 & 4.71 \\
\hline 6.24 & 0.49 & 1.11 & 1.00 & 10.98 \\
\hline 6.32 & 1.90 & 3.55 & 3.55 & 0.03 \\
\hline 7.22 & 0.95 & 4.66 & 4.86 & -4.11 \\
\hline
\end{tabular}

\begin{tabular}{|l|l|r|r|r|}
\hline Mo & Nb & \multicolumn{2}{|l|}{$\begin{array}{l}\text { Prediction } \\
\text { [hr] }\end{array}$} & \multicolumn{2}{l|}{$\begin{array}{l}\text { Experiment } \\
\text { [hr] }\end{array}$} & \multicolumn{1}{l|}{ Error } \\
\hline 4.40 & 1.70 & 0.14 & 0.16 & -10.91 \\
\hline 5.00 & 5.00 & 0.09 & 0.09 & -2.18 \\
\hline 5.28 & 0.85 & 0.25 & 0.19 & 27.56 \\
\hline 5.35 & 1.73 & 0.29 & 0.31 & -8.93 \\
\hline 6.24 & 0.86 & 0.62 & 0.44 & 39.45 \\
\hline 6.33 & 1.75 & 0.66 & 0.69 & -3.26 \\
\hline 7.23 & 0.87 & 1.01 & 0.88 & 14.91 \\
\hline 7.26 & 1.14 & 1.21 & 1.49 & -18.62 \\
\hline Mo & Cr & $\begin{array}{l}\text { Prediction } \\
\text { [hr] }\end{array}$ & $\begin{array}{r}\text { Experiment } \\
\text { [hr] }\end{array}$ \\
\hline 5.30 & 0.48 & 0.50 & 0.40 & Error \\
\hline 6.27 & 0.49 & 0.90 & 0.72 & 24.62 \\
\hline 7.21 & 0.29 & 1.07 & 1.10 & -2.79 \\
\hline 7.26 & 0.49 & 1.32 & 2.37 & -44.32 \\
\hline Mo & Re & $\begin{array}{l}\text { Prediction } \\
\text { [hr] }\end{array}$ & $\begin{array}{l}\text { Experiment } \\
\text { [hr] }\end{array}$ \\
\hline 6.19 & 1.72 & 1.28 & 1.05 & Error \\
\hline 6.22 & 3.45 & 4.59 & 4.22 & 8.82 \\
\hline 7.17 & 1.74 & 2.63 & 2.55 & 3.48 \\
\hline
\end{tabular}

\subsection{Lessons Learned}

During the development of these models, the amount of data necessary to train a model was found to be less than initially expected. The number of points used to generate each curve for model training could be on the order of 80-100. Methods of noise introduction and additional interpolation to increase the number of data points were not found to improve model performance. In addition, it was found that cases with three or more TTT curves for a given alloy could result in successful model development.

A drawback of the basic ANN, like those applied in this work, is the lack of uncertainty estimates that would arise from uncertainties in the experiments. Exploring an approach for uncertainty estimation could be beneficial for producing uncertainty estimates that assist in selecting where additional experiments need to be performed.

In general, the magnitude of error of the binary models is much greater than the ternary models. It is hypothesised that these errors arise from the current approach with these models. There are a 
larger number of studies used in developing the binary model, derived from four studies, as opposed to the ternary alloys derived from two or three studies. This large available pool of data results in a larger variation of processing conditions across the different binary alloys. These processing conditions are not represented with the model at this stage due to a lack of data available in the literature. The models represented in this paper are only trained on weight percent and the isothermal temperature. In order to improve these models, additional inputs are necessary to account for the variety in processing conditions and material thermal-mechanical properties.

\section{Conclusions}

In this paper, MLP models are developed to provide predictive capabilities for isothermal TTT of U-Mo binary and ternary alloys. These model's ability to predict 'novel' U-Mo alloys is shown quite well despite constrasts seen in the literature survey. These models are developed with the primary purpose of informing experimental decisions. These models allow test planners to indentify areas of experimental interest; once initial tests are conducted, the model can be updated and further improve follow-on testing decisions. The model also improves analysis capabilities by reducing the number of data points necessary from any particular test. For example, if one or two isotherms are measured during a test, the model can construct the rest of the TTT curve. This modeling capability further reduces the cost of experiments while also improving the richness of the results from the tests. While this predictive model for time to transformation of U-Mo alloys are the focus on this paper, this thermophysical parameter is only one of many parameters of a fuel material selection trade-off space. So, for many of these alloys, considerations of corrosion, neutronic penalities, and irradiation performance, for example, must also be considered and will be the subject of future research.

The TTT diagrams observed in literature tend to disagree significantly for similar samples. This disagreement has rather deleterious impacts on modeling performance and challenges the ability of modelers in predicting material behavior during processing. These disagreements can be the result of impurities in the base material, which are not reported in any of the datasets, grain size, compositional heteogeneities within the grains, or even residual or applied stresses in the material. The work of Brown et al., 2016 provides a potential approach to measure stresses during transformation, for example [26]. If the material is properly characterized, this information can be used to develop a more robust ANN model. If the cost of performing tests is reduced via the aforementioned use of the MLP model, then additional material characterization can be performed with the same budget. This has implications on further informing the uncertainties that contribute to discrepancies seen in TTT curves, improving the fundamental understanding of TTT dynamics. As additional understanding of phenomena driving TTTs is acquired, this type of MLP model can be used to populate unknowns (such as material impurity) from past literature sources.

\section{Acknowledgements}

The authors would like to acknowledge Mr. Curt Lavender for his review of the manuscript and helpful discussion. We are also grateful for the insight discussion with our reviewers, which has greatly improved the quality of our manuscript. This work was conducted at Pacific Northwest National Laboratory operated by Battelle for the United States Department of Energy under Contract DE-AC05-76RL01830. The work was supported in part by the United States Army Program Executive Office for Simulation, Training, and Instrumentation.

This paper was prepared as an account of work sponsored by an agency of the United States Government. Neither the United States Government nor any agency thereof, nor Battelle Memorial Institute, nor any of their employees, makes any warranty, express or implied, or assumes any legal liability or responsibility for the accuracy, completeness, or usefulness of any information, apparatus, product, or process disclosed, or represents that its use would not 
infringe privately owned rights. Reference herein to any specific commercial product, process, or service by trade name, trademark, manufacturer, or otherwise does not necessarily constitute or imply its endorsement, recommendation, or favoring by the United States Government or any agency thereof, or Battelle Memorial Institute. The views and opinions of authors expressed herein do not necessarily state or reflect those of the United States Government or any agency thereof. 


\section{Appendix}

A compilation of the TTT data is tabulated in Table A.1 and ordered by decreasing $U$ content. Shown is the weight percent of $\mathrm{U}, \mathrm{Mo}$, and the ternary addition along with minimum time of $\alpha-\mathrm{U}$ phase nucleation and the temperature when nucleation occurs. The approximate costs per $\mathrm{kg}$ of ternary addition to the $U$ metal (Mo + ternary) is shown along with the total microscopic crosssection for radiative capture for the ternary constituent only. The costs and cross-sections used are specified in Table A.2.

Table A.1.

Data Table of TTTs for the evaluated ternary alloys. The TTT nose, ternary radiative capture cross-section $(\mathrm{CXS}(\mathrm{n}, \mathrm{g}))$ and expected cost is tabulated. Note that the cost is highly dynamic and only valid as of June 2016, but this result provides a coarse representation.

\begin{tabular}{|c|c|c|c|c|c|c|c|c|c|c|c|}
\hline \multicolumn{3}{|c|}{ Atom Percent } & \multicolumn{3}{|c|}{ Weight Percent } & & \multicolumn{2}{|c|}{ TTT Nose } & \multirow[b]{2}{*}{$\begin{array}{l}\text { Ternary } \\
\text { CXS } \\
(n, g)[b]\end{array}$} & \multirow[b]{2}{*}{$\begin{array}{l}\text { Cost } \\
{[\$ / k g]}\end{array}$} & \multirow[b]{2}{*}{ Legend } \\
\hline $\mathbf{U}$ & Mo & $\mathbf{X}$ & $\mathbf{U}$ & Mo & $X$ & Ternary & $\begin{array}{l}\text { time } \\
\text { [h] }\end{array}$ & $\begin{array}{l}\text { Temp } \\
\text { [C] }\end{array}$ & & & \\
\hline 92.87 & 7.13 & 0.00 & 97.00 & 3.00 & 0.00 & & 0.01 & 517.17 & 0.18 & 16.50 & $<1$ hour \\
\hline 88.45 & 11.55 & 0.00 & 95.00 & 5.00 & 0.00 & & 0.30 & 523.27 & 0.30 & 27.50 & $1-1.9$ hours \\
\hline 86.23 & 11.38 & 2.39 & 94.00 & 5.00 & 1.00 & $\mathrm{Zr}$ & 0.11 & 510.01 & 0.30 & 51.50 & 2-2.9 hours \\
\hline 86.00 & 12.00 & 2.00 & 93.87 & 5.28 & 0.85 & $\mathrm{Nb}$ & 0.19 & 503.73 & 0.33 & 44.72 & 3-3.9 hours \\
\hline 86.00 & 10.00 & 4.00 & 93.75 & 4.39 & 1.85 & $\mathrm{Ru}$ & 0.50 & 511.94 & 0.37 & 510.96 & 4-5.9 hours \\
\hline 86.00 & 10.00 & 4.00 & 93.89 & 4.40 & 1.70 & $\mathrm{Nb}$ & 0.15 & 505.36 & 0.30 & 55.57 & 6-6.9 hours \\
\hline 86.00 & 12.00 & 2.00 & 94.22 & 5.30 & 0.48 & $\mathrm{Cr}$ & 0.26 & 527.37 & 0.37 & 29.15 & $7+$ hours \\
\hline 86.00 & 12.00 & 2.00 & 93.80 & 5.28 & 0.93 & $\mathrm{Ru}$ & 0.43 & 516.42 & 0.36 & 272.52 & \\
\hline 84.88 & 14.08 & 1.04 & 93.28 & 6.24 & 0.49 & $\mathrm{Ru}$ & 0.98 & 503.33 & 0.39 & 161.81 & \\
\hline 84.26 & 15.74 & 0.00 & 93.00 & 7.00 & 0.00 & & 1.06 & 526.05 & 0.41 & 38.50 & \\
\hline 84.00 & 12.00 & 4.00 & 92.78 & 5.34 & 1.88 & $\mathrm{Ru}$ & 1.09 & 502.31 & 0.42 & 522.59 & \\
\hline 84.00 & 12.00 & 4.00 & 92.92 & 5.35 & 1.73 & $\mathrm{Nb}$ & 0.31 & 506.42 & 0.36 & 61.21 & \\
\hline 84.00 & 14.00 & 2.00 & 92.10 & 6.19 & 1.72 & $\mathrm{Re}$ & 1.02 & 506.40 & 2.16 & 1234.81 & \\
\hline 84.00 & 14.00 & 2.00 & 93.25 & 6.27 & 0.49 & $\mathrm{Cr}$ & 0.50 & 525.93 & 0.42 & 34.46 & \\
\hline 84.00 & 14.00 & 2.00 & 92.90 & 6.24 & 0.86 & $\mathrm{Nb}$ & 0.42 & 512.87 & 0.38 & 50.21 & \\
\hline 84.00 & 16.00 & 0.00 & 92.87 & 7.13 & 0.00 & & 0.20 & 511.62 & 0.41 & 39.22 & \\
\hline 82.80 & 16.00 & 1.20 & 92.50 & 7.21 & 0.29 & $\mathrm{Cr}$ & 1.02 & 507.34 & 0.45 & 39.63 & \\
\hline 82.25 & 17.75 & 0.00 & 92.00 & 8.00 & 0.00 & & 0.91 & 504.71 & 0.46 & 44.00 & \\
\hline 82.25 & 17.75 & 0.00 & 92.00 & 8.00 & 0.00 & & 0.62 & 498.13 & 0.46 & 44.00 & \\
\hline 82.25 & 17.75 & 0.00 & 92.00 & 8.00 & 0.00 & & 1.68 & 523.05 & 0.46 & 44.00 & \\
\hline 82.16 & 15.51 & 2.33 & 92.00 & 7.00 & 1.00 & $\mathrm{Zr}$ & 0.21 & 514.41 & 0.40 & 62.50 & \\
\hline 82.00 & 14.00 & 4.00 & 90.34 & 6.22 & 3.45 & $\mathrm{Re}$ & 3.58 & 513.44 & 3.96 & 2447.24 & \\
\hline 82.00 & 14.00 & 4.00 & 91.92 & 6.33 & 1.75 & $\mathrm{Nb}$ & 0.66 & 510.04 & 0.41 & 67.00 & \\
\hline 82.00 & 14.00 & 4.00 & 91.78 & 6.32 & 1.90 & $\mathrm{Ru}$ & 3.49 & 496.23 & 0.47 & 534.54 & \\
\hline 82.00 & 16.00 & 2.00 & 91.91 & 7.23 & 0.86 & $\mathrm{Zr}$ & 0.29 & 519.05 & 0.42 & 60.38 & \\
\hline 82.00 & 16.00 & 2.00 & 91.10 & 7.17 & 1.74 & $\mathrm{Re}$ & 2.43 & 507.36 & 2.21 & 1256.08 & \\
\hline 82.00 & 16.00 & 2.00 & 92.25 & 7.26 & 0.49 & $\mathrm{Cr}$ & 1.85 & 517.71 & 0.47 & 39.91 & \\
\hline 82.00 & 16.00 & 2.00 & 91.90 & 7.23 & 0.87 & $\mathrm{Nb}$ & 0.82 & 509.88 & 0.44 & 55.85 & \\
\hline 82.00 & 16.00 & 2.00 & 91.83 & 7.22 & 0.95 & $\mathrm{Ru}$ & 4.65 & 513.48 & 0.47 & 289.75 & \\
\hline 82.00 & 18.00 & 0.00 & 91.87 & 8.13 & 0.00 & & 1.21 & 504.31 & 0.46 & 44.72 & \\
\hline 81.97 & 11.05 & 6.97 & 92.00 & 5.00 & 3.00 & $\mathrm{Zr}$ & 0.03 & 501.30 & 0.30 & 99.50 & \\
\hline 81.40 & 16.00 & 2.60 & 91.60 & 7.26 & 1.14 & $\mathrm{Nb}$ & 1.49 & 507.57 & 0.44 & 60.93 & \\
\hline 80.12 & 15.29 & 4.59 & 91.00 & 7.00 & 2.00 & $\mathrm{Zr}$ & 0.12 & 520.11 & 0.40 & 86.50 & \\
\hline 78.39 & 21.61 & 0.00 & 90.00 & 10.00 & 0.00 & & 6.55 & 505.42 & 0.56 & 55.00 & \\
\hline 78.39 & 21.61 & 0.00 & 90.00 & 10.00 & 0.00 & & 4.98 & 492.78 & 0.56 & 55.00 & \\
\hline 78.13 & 15.08 & 6.80 & 90.00 & 7.00 & 3.00 & $\mathrm{Zr}$ & 0.08 & 517.76 & 0.40 & 110.50 & \\
\hline 78.11 & 10.77 & 11.12 & 90.00 & 5.00 & 5.00 & $\mathrm{Nb}$ & 0.08 & 505.04 & 0.41 & 119.50 & \\
\hline 76.45 & 21.31 & 2.24 & 89.00 & 10.00 & 1.00 & $\mathrm{Zr}$ & 0.66 & 500.12 & 0.55 & 79.00 & \\
\hline 74.84 & 25.16 & 0.00 & 88.00 & 12.00 & 0.00 & & 18.26 & 502.72 & 0.65 & 66.00 & \\
\hline 74.56 & 21.02 & 4.42 & 88.00 & 10.00 & 2.00 & $\mathrm{Zr}$ & 0.19 & 510.75 & 0.55 & 103.00 & \\
\hline
\end{tabular}




\begin{tabular}{|l|r|r|r|r|r|r|r|r|r|r|}
70.93 & 20.46 & 8.61 & 86.00 & 10.00 & 4.00 & $\mathrm{Zr}$ & 0.07 & 509.92 & 0.55 & 151.00 \\
\hline 67.49 & 19.93 & 12.58 & 84.00 & 10.00 & 6.00 & $\mathrm{Zr}$ & 0.05 & 509.08 & 0.54 & 199.00 \\
\hline
\end{tabular}

In Table A.2, the general effect of the ternary addition on phase stability is shown, along with the atomic radius, radiative capture cross-section, and the cost per unit mass of the element. The effect of the ternary addition is specified as positive $(P)$ or negative $(N)$ in that it either stabilizes $(\mathrm{P})$ or destabilizes $(\mathrm{N})$ the gamma phase.

Table A.2.

The effect of ternary addtion on phase stability along with the atomic radius, thermal radiative capture cross-section (CXS), and estimated cost.

\begin{tabular}{|c|c|c|c|c|c|c|c|c|c|c|c|}
\hline \multicolumn{2}{|c|}{$\mathrm{Ti}$} & \multicolumn{2}{|c|}{ V } & \multicolumn{2}{|c|}{$\mathrm{Cr}$} & \multicolumn{2}{|c|}{ Mn } & \multicolumn{2}{|c|}{$\mathrm{Fe}$} & \multicolumn{2}{|c|}{ Legend } \\
\hline & & & & $P$ & 1.39 & & & & & Effect & Radius \\
\hline & & & & 3.1 & 0 & & & & & CXS & $\begin{array}{l}\text { Cost } \\
(\$ / g)\end{array}$ \\
\hline \multicolumn{2}{|c|}{$\mathrm{Zr}$} & \multicolumn{2}{|c|}{$\mathrm{Nb}$} & \multicolumn{2}{|c|}{ Mo } & \multicolumn{2}{|c|}{ Tc } & \multicolumn{2}{|c|}{$\mathbf{R u}$} & & \\
\hline $\mathrm{N}$ & 1.75 & $\mathrm{~N}$ & 1.64 & $\mathrm{P}$ & 1.54 & & & $\mathrm{P}$ & 1.42 & & \\
\hline 0.19 & 2.4 & 1.2 & 1.8 & 2.58 & 0.55 & & & 2.7 & 26.3 & & \\
\hline \multicolumn{2}{|c|}{$\mathrm{Hf}$} & \multicolumn{2}{|c|}{ Ta } & \multicolumn{2}{|c|}{$\mathbf{W}$} & \multicolumn{2}{|c|}{$\mathbf{R e}$} & \multicolumn{2}{|c|}{ Os } & & \\
\hline & & & & & & $\mathrm{P}$ & 1.51 & & & & \\
\hline & & & & & & 90 & 70 & & & & \\
\hline
\end{tabular}




\section{References}

[1] S. Neogy et al., "Microstructural study of gamma phase stability in U-9 wt.\% Mo alloy," Journal of Nuclear Materials, vol. 422, no. 1-3, pp. 77-85, Mar. 2012.

[2] S. Neogy, M. T. Saify, S. K. Jha, D. Srivastava, and G. K. Dey, "Ageing characteristics of the metastable gamma phase in U-9 wt.\% Mo alloy: experimental observations and thermodynamic validation," Philosophical Magazine, vol. 95, no. 26, pp. 2866-2884, Sep. 2015.

[3] S. T. Konobeevsky, N. F. Pravdyuk, and V. I. Kutaitsev, "Irradiation of Fissionable Materials," in Proceedings of the International Conference on the Peaceful Uses of Atomic Energy, United Nations, 1956, vol. 7, pp. 433-440.

[4] R. M. Willard and A. R. Schmitt, "Irradiation Swelling, Phase Reversion, and Intergranular Cracking of U-10 Wt.\% Mo Fuel Alloy," Atomics International. Div. of North American Aviation, Inc., Canoga Park, Calif., NAA-SR-8956, Feb. 1965.

[5] C. A. W. Peterson, W. J. Steele, and S. L. DiGiallonardo, "Isothermal Transformation Study of Some Uranium-Base Alloys," University of California, Livermore, CA, UCRL-7824, Aug. 1964.

[6] G. L. Hofman, M. K. Meyer, and A. E. Ray, "Design of High Density Gamma-Phase Uranium Alloys for Leu Dispersion Fuel Applications.," Argonne National Lab., IL (US), ANL/TD/CP97494, Oct. 1998.

[7] B. N. Briggs, W. H. Friske, North American Aviation., and U.S. Atomic Energy Commission., Development of niobium diffusion barriers for aluminum-clad uranium alloy fuel elements. Canoga Park, California: Atomics International, 1962.

[8] V. W. Storhok, A. A. Bauer, and R. F. Dickerson, "SURVEY OF TERNARY AND QUATERNARY METASTABLE GAMMA-PHASE URANIUM ALLOYS," Battelle Memorial Institute, Columbus, Ohio, BMI-1278, Jul. 1958.

[9] A. A. AlQuraishi and E. M. Shokir, "Artificial neural networks modeling for hydrocarbon gas viscosity and density estimation," Journal of King Saud University - Engineering Sciences, vol. 23, no. 2, pp. 123-129, Jun. 2011.

[10] A. R. Moghadassi, M. R. Nikkholgh, F. Parvizian, and S. M. Hosseini, "Estimation of thermophysical properties of dimethyl ether as a commercial refrigerant based on artificial neural networks," Expert Systems with Applications, vol. 37, no. 12, pp. 7755-7761, Dec. 2010.

[11] A. Şencan, I. İ. Köse, and R. Selbaş, "Prediction of thermophysical properties of mixed refrigerants using artificial neural network," Energy Conversion and Management, vol. 52, no. 2, pp. 958-974, Feb. 2011.

[12] W. S. Andrews, B. J. Lewis, and D. S. Cox, "Artificial neural network models for volatile fission product release during severe accident conditions," Journal of Nuclear Materials, vol. 270, no. 1-2, pp. 74-86, Apr. 1999.

[13] N. Castin, L. Malerba, and R. Chaouadi, "Prediction of radiation induced hardening of reactor pressure vessel steels using artificial neural networks," Journal of Nuclear Materials, vol. 408, no. 1, pp. 30-39, Jan. 2011.

[14] Y.-H. Koo, J.-Y. Oh, B.-H. Lee, Y.-W. Tahk, and K.-W. Song, "Artificial neural network modeling for fission gas release in LWR UO2 fuel under RIA conditions," Journal of Nuclear Materials, vol. 405, no. 1, pp. 33-43, Oct. 2010.

[15] P. Angelo, "Representing Nuclear Criticality Excursion Experiment Data by an Artificial Neural Network," Nuclear Technology, 2015.

[16] D. Burkes et al., "Improved Alloy Test Plan: Low Enriched Uranium Pulse Reactor Project," Pacific Northwest National Laboratory, PNNL-25550, Jul. 2016.

[17] L. V. Fausett, Fundamentals of Neural Networks: Architectures, Algorithms And Applications, 1 edition. Pearson, 1993.

[18] K. He, X. Zhang, S. Ren, and J. Sun, "Delving Deep into Rectifiers: Surpassing Human-Level Performance on ImageNet Classification," arXiv:1502.01852 [cs], Feb. 2015.

[19] A. Mass, A. Hannun, and A. Ng, "Rectifier Nonlinearities Improve Neural Network Acoustic Models," in Proceedings of the 30th International Conference on Machine Learning, Atlanta, Georgia USA, 2013, vol. 28. 
[20] X. Glorot and Y. Bengio, "Understanding the difficulty of training deep feedforward neural networks," in In Proceedings of the International Conference on Artificial Intelligence and Statistics (AISTATS'10). Society for Artificial Intelligence and Statistics, 2010.

[21] D. Kingma and J. Ba, "Adam: A Method for Stochastic Optimization," arXiv:1412.6980 [cs], Dec. 2014.

[22] G. Cabane and G. Donze, "Stabilisation de la phase y dans les alliages ternaires a base d'uranium-molybdene," Journal of Nuclear Materials, vol. 4, pp. 364-373, Jul. 1959.

[23] P. E. Repas, R. H. Goodenew, and R. F. Hehemann, "Transformation Characteristics of U-Mo and U-Mo-Ti Alloys," Trans. Am. Soc. Metals, vol. 57, 1964.

[24] M. A. Steiner, C. A. Calhoun, R. W. Klein, K. An, E. Garlea, and S. R. Agnew, "a-Phase transformation kinetics of $U-8$ wt $\%$ Mo established by in situ neutron diffraction," Journal of Nuclear Materials, vol. 477, pp. 149-156, Aug. 2016.

[25] A. E. Dwight, "The uranium-molybdenum equilibrium diagram below $900^{\circ} \mathrm{C}$," Journal of Nuclear Materials, vol. 2, no. 1, pp. 81-87, Mar. 1960.

[26] D. W. Brown, M. A. Okuniewski, B. Clausen, G. A. Moore, and T. A. Sisneros, "Neutron diffraction measurement of residual stresses in Al-clad U-10Mo fuel plates," Journal of Nuclear Materials, vol. 474, pp. 8-18, Jun. 2016. 